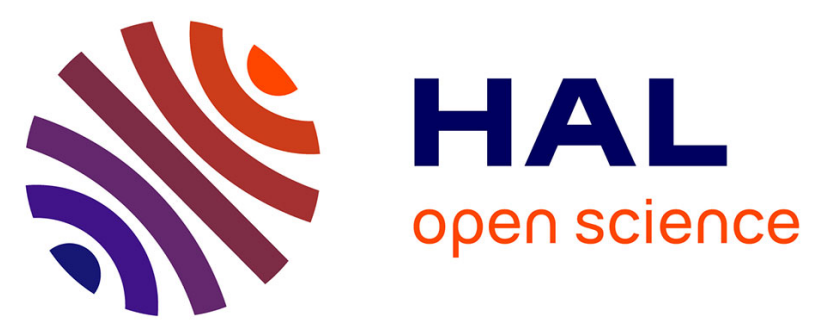

\title{
Antioxidant activity of olive phenols and other dietary phenols in model gastric conditions: Scavenging of the free radical DPPH and inhibition of the haem-induced peroxidation of linoleic acid
}

Sabiha Achat, Njara Rakotomanomana, Khodir Madani, Olivier O. Dangles

\section{To cite this version:}

Sabiha Achat, Njara Rakotomanomana, Khodir Madani, Olivier O. Dangles. Antioxidant activity of olive phenols and other dietary phenols in model gastric conditions: Scavenging of the free radical DPPH and inhibition of the haem-induced peroxidation of linoleic acid. Food Chemistry, 2016, 213, pp.135-142. 10.1016/j.foodchem.2016.06.076 . hal-02637042

\author{
HAL Id: hal-02637042 \\ https://hal.inrae.fr/hal-02637042
}

Submitted on 27 May 2020

HAL is a multi-disciplinary open access archive for the deposit and dissemination of scientific research documents, whether they are published or not. The documents may come from teaching and research institutions in France or abroad, or from public or private research centers.
L'archive ouverte pluridisciplinaire HAL, est destinée au dépôt et à la diffusion de documents scientifiques de niveau recherche, publiés ou non, émanant des établissements d'enseignement et de recherche français ou étrangers, des laboratoires publics ou privés. 


\title{
Antioxidant activity of olive phenols and other dietary phenols in model gastric conditions: Scavenging of the free radical DPPH and inhibition of the haem-induced peroxidation of linoleic acid
}

\author{
Sabiha Achat ${ }^{a}$, Njara Rakotomanomana ${ }^{b}$, Khodir Madani ${ }^{a}$, Olivier Dangles ${ }^{\mathrm{b}, *}$ \\ ${ }^{a}$ Laboratory of Biomathematics, Biochemistry, Biophysics and Scientometrics, Faculty of Natural Sciences and Life, University of Bejaia, Bejaia 06000, Algeria \\ ${ }^{\mathrm{b}}$ University of Avignon, INRA, UMR408, Safety \& Quality of Plant Products, 84000 Avignon, France
}

Keywords:

Phenols

Olive

Antioxidant

$\mathrm{DPPH}$

Metmyoglobin

Lipid peroxidation

Haem

\begin{abstract}
A B S T R A C T
The antioxidant activity of dietary phenols in humans (direct reduction of radicals and other highly oxidizing species) could be largely restricted to fighting postprandial oxidative stress in the gastric compartment. Hence, the development of chemical tests simply modelling this situation is pertinent. In this work, the antioxidant properties of the olive phenols hydroxytyrosol and oleuropein are investigated in $\mathrm{pH}$ 5-6 micellar solutions through the reduction of the DPPH radical and the inhibition of the metmyoglobininduced peroxidation of linoleic acid. In the first test, hydroxytyrosol and oleuropein proved as efficient as common polyphenols and their reactivity was only moderately affected by $\beta$-cyclodextrin and bovine serum albumin, taken as models of food macromolecules. In the second test, hydroxytyrosol and oleuropein by themselves came up as relatively weak inhibitors, despite their efficiency at reducing hypervalent haem iron. However, hydroxytyrosol was able to act in synergy with the typical chain-breaking antioxidant $\alpha$-tocopherol.
\end{abstract}

\section{Introduction}

Olive phenols are important components of a healthy Mediterranean diet (Visioli \& Bernardini, 2011) and are especially beneficial according a health claim issued by the European Food Safety Authority (EFSA, 2011). Oleuropein (Fig. 1 supplementary) is a typical phenol of the olive fruit. However, upon oil processing, its enzymatic hydrolysis takes place, so that hydroxytyrosol (up to $0.2 \mathrm{mM}$ in certain virgin olive oils) is actually much more abundant than oleuropein in olive oil and its by-products (Jerman Klen, Golc Wondra, Vrhovsek, Sivilotti, \& Mozetic Vodopivec, 2015; Sanchez de Medina, Priego-Capote, \& Luque de Castro, 2015).

The protection against cardiovascular and metabolic diseases provided by hydroxytyrosol and oleuropein has been convincingly demonstrated in animal and human studies (Bulotta et al., 2014). The mechanisms involved are certainly manifold, interrelated and largely sustained by the true circulating metabolites (instead of the native forms), e.g. the $\mathrm{O}$-glucuronides of hydroxytyrosol (Giordano, Dangles, Rakotomanomana, Baracchini, \& Visioli,

\footnotetext{
* Corresponding author.

E-mail address: olivier.dangles@univ-avignon.fr (O. Dangles).
}

2015; Orozco-Solano, Ferreiro-Vera, Priego-Capote, \& Luque de Castro, 2012).

As human and bacterial metabolism (e.g., deoxygenation by the microbiota and conjugation of phenolic $\mathrm{OH}$ groups in the intestine and liver) (Del Rio et al., 2013) is expected to lower the redox activity of dietary phenols, it is now unlikely that their post-absorption health effects be mostly driven by the antioxidant activity, at least in its usual meaning of direct scavenging of reactive oxygen species involved in oxidative stress. By contrast, upstream antioxidant effects during food processing, storage and digestion remain important issues involving native phenolic compounds. In particular, postprandial oxidative stress may occur as early as in the stomach itself where combinations of dietary (haem) iron, polyunsaturated lipids (inevitably contaminated by a fraction of lipid hydroperoxides), acidity and dioxygen in non-limiting concentration can create favourable conditions for polyunsaturated lipid peroxidation, itself responsible for a lower nutritional value of the dietary bolus and an accumulation of potentially toxic lipid oxidation products (Gobert et al., 2014; Kanner, Gorelik, Roman, \& Kohen, 2012). Owing to their abundance in plant food, electrondonating phenolic compounds could be important micronutrients for fighting oxidative stress in the stomach (Dangles, 2012). However, given their general affinity for proteins and polysaccharides, their antioxidant activity is susceptible to 
modulation by binding to the plant matrix and to other components of the dietary bolus.

In this work, the typical olive phenols hydroxytyrosol and oleuropein (Fig. 1 supplementary) are tested for their ability to a) reduce the DPPH radical and ferrylmyoglobin (hypervalent haem iron) and b) inhibit the haem-induced peroxidation of linoleic acid (in the presence or absence of $\alpha$-tocopherol) in mildly acidic micellar solutions simply modelling the gastric content. The influence of the cyclic oligosaccharide $\beta$-cyclodextrin ( $\beta-C D$, a starch model) and of bovine serum albumin (BSA) is also reported. Comparison with the common phenolic antioxidants quercetin, rutin, catechin and chlorogenic acid (Fig. 1 supplementary) is also provided.

\section{Materials and methods}

\subsection{Chemicals and reagents}

Rutin hydrate (95\%), chlorogenic acid (97\%), quercetin dihydrate (98\%), oleuropein, $\alpha$-tocopherol, polyoxyethyleneglycol 23 lauryl ether (Brij ${ }^{\circledR} 35$, mean MM $1200 \mathrm{~g} \mathrm{~mol}^{-1}$ ), 1,1-diphenyl-2picrylhydrazyl (DPPH, >90\%), $\beta$-cyclodextrin ( $\beta$-CD), (9Z,12Z)octadecadienoic acid (linoleic acid, $>99 \%$ ), bovine serum albumin (BSA, fraction V A-9647, MW ca. 66,500 $\mathrm{g} \mathrm{mol}^{-1}$ ), myoglobin from equine heart ( $>90 \%$, salt-free), and $\mathrm{H}_{2} \mathrm{O}_{2}(30 \%)$ were purchased from Sigma-Aldrich (USA). Catechin hydrate (+96\%) was from Fluka (France). Hydroxytyrosol was kindly provided by Pr. F. Visioli and Seprox Biotech (Madrid, Spain). Stock metmyoglobin solutions were prepared in Milli-Q water, filtered through a $0.45 \mu \mathrm{m}$ filter and their concentrations checked by absorbance measurement at $525 \mathrm{~nm}$ using $\varepsilon=7700 \mathrm{M}^{-1} \mathrm{~cm}^{-1}$ (Mikkelsen \& Skibsted, 1995).

\subsection{UV-visible spectroscopy}

UV-visible spectra were recorded on an Agilent 8453 diode-array spectrometer equipped with a magnetically stirred quartz cell (optical pathlength: $1 \mathrm{~cm}$ ). The temperature in the cell was kept at $25{ }^{\circ} \mathrm{C}$ (DPPH test, reduction of ferrylmyoglobin) or at $37^{\circ} \mathrm{C}$ (lipid peroxidation) by means of a thermostated bath.

\subsection{Dioxygen consumption}

Analyses were carried out with help of an optic fibre probe (oxygen Microoptode, PreSens) directly inserted into the magnetically stirred solution. The $\mathrm{O}_{2}$ concentration was recorded by a Microx TX3 oxygen meter (PreSens).

\subsection{Scavenging of the DPPH radical in micelles}

Solutions of DPPH (300 $\mu \mathrm{M})$ and phenols (50 or $150 \mu \mathrm{M})$ were individually prepared in an acetate buffer $(0.1 \mathrm{M}, \mathrm{pH} 5)$ containing the non-ionic surfactant $\mathrm{Brij}^{\circledR} 35(20 \mathrm{mM})$. Phenol solutions containing BSA $(250 \mu \mathrm{M})$ or $\beta$-CD $(250 \mu \mathrm{M})$ were also used. To $1 \mathrm{~mL}$ of a freshly prepared solution of DPPH placed in the spectrometer cell was added $1 \mathrm{~mL}$ of the phenol solution (DPPH/phenol molar ratio $=2$ or 6 ). Spectra were recorded every $0.5 \mathrm{~s}$ over $2 \mathrm{~min}$ for the determination of the rate constants and partial stoichiometries (fast step). Kinetic runs of $60 \mathrm{~min}$ were used for the determination of total stoichiometries. Calculations were carried out according to our previous work (Goupy, Dufour, Loonis, \& Dangles, 2003).

\subsection{Reduction of ferrylmyoglobin}

The experimental procedure for the formation of ferrylmyoglobin and its subsequent reduction by phenols was the same as in our previous work (Lorrain, Dufour, \& Dangles, 2010). Two mL of a $60 \mu \mathrm{M}$ solution of metmyoglobin and BSA (3 equiv.) in the pH 5.8 phosphate buffer were placed into the spectrophotometer cell. Then, $30 \mu \mathrm{L}$ of a concentrated aqueous solution of $\mathrm{H}_{2} \mathrm{O}_{2}$ ( $4 \mathrm{mM}$, concentration determined par UV-visible spectroscopy using $\varepsilon=39.4 \mathrm{M}^{-1} \mathrm{~cm}^{-1}$ at $240 \mathrm{~nm}$ ) were added (final $\mathrm{H}_{2} \mathrm{O}_{2}$ concentration in the cell $=60 \mu \mathrm{M})$. The conversion of metmyoglobin into ferrylmyoglobin $\left(\mathrm{MbFe}^{\mathrm{IV}}=0\right.$ ) was monitored by measuring the increase in absorbance at $590 \mathrm{~nm}$ over a few minutes. Finally, $20 \mu \mathrm{L}$ of a concentrated solution of phenol in $\mathrm{MeOH}$ (final concentrations in the cell: 25 and $60 \mu \mathrm{M}$ ) were added and the reduction of ferrylmyoglobin was monitored at $590 \mathrm{~nm}$.

\subsection{Inhibition of the haem-induced peroxidation of linoleic acid}

Given volumes of daily prepared solutions of linoleic acid $(70 \mathrm{mM})$ and antioxidant $(0.2 \mathrm{mM})$ in $\mathrm{MeOH}$ were mixed with a stock solution of $\mathrm{Brij}^{\circledR} 35(0.4 \mathrm{mM})$ in a phosphate buffer ( $\mathrm{pH} 5.8$ ). The final concentrations in the solution were $0.7 \mathrm{mM}$ linoleic acid, and $0.2-1 \mu \mathrm{M}$ antioxidant. Two $\mathrm{mL}$ of the freshly prepared solution were transferred to the spectrometer cell. At time $0,20 \mu \mathrm{L}$ of $50 \mu \mathrm{M}$ metmyoglobin (final concentration in the cell: $0.5 \mu \mathrm{M}$ ) was added to the sample under constant magnetic stirring and the UV-visible spectra were recorded at regular time intervals (Sy et al., 2013). Concomitantly, $\mathrm{O}_{2}$ concentration was monitored in the solution by an optic fibre probe.

\subsection{Data analysis}

The curve-fittings of the absorbance $v s$. time plots were carried out on a PC using the Scientist program (MicroMath, Salt Lake City, USA). Beer's law and sets of differential kinetic equations (see text for the kinetic models used) with initial conditions on concentrations were input in the model. Curve-fittings were achieved through least square regression and yielded optimized values for the parameters (kinetic rate constants, molar absorption coefficients, stoichiometries). All experiments were conducted in triplicates and results are expressed as mean \pm standard deviation (SD). Good $(>0.99)$ to excellent $(>0.999)$ correlation coefficients were typically obtained.

\section{Results and discussion}

\subsection{Scavenging of DPPH radical in aqueous micellar solution}

DPPH is a stable free radical that is widely used in alcoholic solutions for a simple estimation of the antioxidant capacity of phenols through their ability to deliver $\mathrm{H}$-atoms and/or electrons. However, the insolubility of DPPH in water limits its applications in more elaborate antioxidant tests. For solubilization in aqueous solution, DPPH was incorporated into micelles of the non-ionic surfactant Brij35 $\left(\mathrm{C}_{12} \mathrm{H}_{25}-\left(\mathrm{OCH}_{2}-\mathrm{CH}_{2}\right)_{23}-\mathrm{OH}\right)$. Thus, the influence of $\mathrm{pH}$ and of dietary macromolecules (possibly interacting with phenols in food and in the digestive tract) on the DPPH-scavenging reaction of phenols could be investigated.

A $20 \mathrm{mM}$ Brij35 solution in acetate buffer $(0.1 \mathrm{M}, \mathrm{pH} 5)$ proved appropriate for solubilizing DPPH over a convenient range of concentration up to $150 \mu \mathrm{M}$ (linear Beer's plot at $529 \mathrm{~nm}$ ). Above this concentration, a saturation of the visible absorbance was observed, pointing to the onset of DPPH aggregation. Thus, $150 \mu \mathrm{M}$ DPPH solutions in Brij35-containing acetate buffer were used for all experiments. At this concentration, the DPPH visible absorption band was both stable and reproducible. In those conditions, the maximum absorption wavelength of DPPH is $529 \mathrm{~nm}$ with a molar absorption coefficient of $10,700 \mathrm{M}^{-1} \mathrm{~cm}^{-1}$. Close $\varepsilon$ values were measured in $\mathrm{MeOH}$ and in $\mathrm{pH} 4.6$ CTAB micellar solution (Goupy 
et al., 2003; Noipa, Srijaranai, Tuntulani, \& Ngeontae, 2011). The $\lambda_{\max }$ shift from $515 \mathrm{~nm}$ in $\mathrm{MeOH}$ to $c a .530 \mathrm{~nm}$ in micellar to $c a$. $550 \mathrm{~nm}$ in aqueous solution (Noipa et al., 2011) suggests that the micellar solution displays a polarity that is intermediate between those of $\mathrm{MeOH}$ and water.

The decay of the DPPH visible band following the addition of an antioxidant (Fig. 2 supplementary) can be analyzed according to the model proposed by Goupy et al. (2003). The rate constant $k_{1}$ for the first $\mathrm{H}$-atom abstraction from the antioxidant and the partial antioxidant stoichiometry $n$, which can be defined as the number of $\mathrm{H}$-atoms transferred during the fast step of DPPH consumption (1-2 min, i.e. transfer of the antioxidant's most labile $\mathrm{H}$-atoms), can thus be estimated (antioxidant concentration used in the curve-fittings $=n \times$ experimental concentration). Experiments extending over $60 \mathrm{~min}$ were then used for the determination of the total antioxidant stoichiometry $\left(n_{\text {tot }}=\left(A_{\text {initial }}-A_{\text {final }}\right) /\left(\varepsilon_{\text {DPPH }} \times\right.\right.$ antioxidant concentration $)$, as some oxidation products formed during the fast step usually retain a substantial H-donating capacity.

As seen in Table 1, at the end of the fast step, the number of DPPH radicals reduced per antioxidant molecules $(n)$ is about 2 , which corresponds to the transfer of the two labile H-atoms of the catechol nucleus. Furthermore, total stoichiometries $\left(n_{\text {tot }}\right)$ are in the range $3-5$. The relatively high $k_{1}$ values confirmed that the selected phenols were potent $\mathrm{H}$-atom donors. Indeed, upon transfer of the most labile $\mathrm{H}$-atom, antioxidants containing a catechol group (1,2-dihydroxybenzene) are converted into 0 -semiquinones, which are stabilized by a combination of electronic and intramolecular H-bonding effects (Dangles, 2012). Moreover, quercetin $\left(k_{1} \approx 37 \times 10^{2} \mathrm{M}^{-1} \mathrm{~s}^{-1}\right)$ and rutin $\left(k_{1} \approx 29 \times 10^{2} \mathrm{M}^{-1} \mathrm{~s}^{-1}\right)$ are more reactive than catechin $\left(k_{1} \approx 17 \times 10^{2} \mathrm{M}^{-1} \mathrm{~s}^{-1}\right)$, which underlines that the semiquinone radicals of the flavonols are stabilized by extended electron conjugation involving the C-ring. This hierarchy is in agreement with that observed in MeOH (Goupy et al., 2003). Furthermore, quercetin displays a higher total stoichiometry $\left(n_{\text {tot }}=5\right)$ than rutin and catechin $\left(n_{\text {tot }} \approx 4\right)$, thus confirming the participation of $\mathrm{C} 3-\mathrm{OH}$ in the $\mathrm{H}$-atom transfer reactions. Interestingly, oleuropein (despite the absence of extended electronic delocalization in its semiquinone) is as reactive as quercetin in the transfer of its first H-atom to DPPH and seems even more potent than its derivative hydroxytyrosol. This observation suggests a favourable positioning of oleuropein in the micelles. By contrast, in $\mathrm{MeOH}$,

\section{Table 1}

$\mathrm{H}$-atom transfer from dietary phenols to DPPH in micelles and the influence of BSA and $\beta$-cyclodextrin ( $0.1 \mathrm{M}$ acetate buffer, $20 \mathrm{mM}$ Brij35, pH 5, $25^{\circ} \mathrm{C}, \mathrm{N}=3$ ).

\begin{tabular}{llll}
\hline Antioxidant & $k_{1} / \mathrm{M}^{-1} \mathrm{~s}^{-1}$ a & $n^{\mathrm{a}}$ & $n_{\text {tot }}{ }^{\mathrm{a}}$ \\
\hline BSA & $6.6( \pm 0.1)$ & - & $1.66( \pm 0.03)$ \\
Quercetin & $3716( \pm 251)$ & $1.75( \pm 0.02)$ & $5.05( \pm 0.01)$ \\
Quercetin + BSA & $2775( \pm 35)$ & $1.63( \pm 0.01)$ & $4.65( \pm 0.02)$ \\
Quercetin + $\beta-C D$ & $881( \pm 108)$ & $1.81( \pm 0.20)$ & $4.20( \pm 0.10)$ \\
Rutin & $2917( \pm 10)$ & $1.39( \pm 0.01)$ & $3.65( \pm 0.06)$ \\
Rutin + BSA & $1781( \pm 16)$ & $1.59( \pm 0.01)$ & $3.38( \pm 0.03)$ \\
Rutin + $\beta-C D$ & $1746( \pm 92)$ & $1.38( \pm 0.02)$ & $3.75( \pm 0.15)$ \\
Catechin & $1689( \pm 112)$ & $1.59( \pm 0.06)$ & $3.56( \pm 0.13)$ \\
Catechin + BSA & $1303( \pm 66)$ & $1.55( \pm 0.07)$ & $2.63( \pm 0.29)$ \\
Catechin + $\beta-C D$ & $1112( \pm 20)$ & $1.32( \pm 0.20)$ & $3.91( \pm 0.07)$ \\
Chlorogenic acid & $2556( \pm 176)$ & $1.61( \pm 0.01)$ & $2.99( \pm 0.11)$ \\
Chlorogenic acid + BSA & $1904( \pm 74)$ & $1.71( \pm 0.02)$ & $2.97( \pm 0.07)$ \\
Chlorogenic acid + $\beta-C D$ & $2502( \pm 11)$ & $1.65( \pm 0.01)$ & $2.08( \pm 0.21)$ \\
Oleuropein & $3703( \pm 246)$ & $1.67( \pm 0.01)$ & $2.81( \pm 0.05)$ \\
Oleuropein + BSA & $4960( \pm 244)$ & $1.65( \pm 0.01)$ & $3.63( \pm 0.07)$ \\
Oleuropein + $\beta-C D$ & $3359( \pm 156)$ & $1.66( \pm 0.01)$ & $3.06( \pm 0.21)$ \\
Hydroxytyrosol & $1808( \pm 69)$ & $1.61( \pm 0.01)$ & $2.78( \pm 0.03)$ \\
Hydroxytyrosol + BSA & $2103( \pm 146)$ & $1.73( \pm 0.01)$ & $3.16( \pm 0.09)$ \\
Hydroxytyrosol + $\beta-C D$ & $1912( \pm 46)$ & $1.67( \pm 0.04)$ & $2.94( \pm 0.21)$ \\
\hline
\end{tabular}

a Evaluated with 2 equiv. of DPPH.

b Evaluated with 6 equiv. of DPPH. quercetin is as expected a better $\mathrm{H}$-atom donor than oleuropein (Goupy et al., 2003; Roche, Dufour, Mora, \& Dangles, 2005).

The high total stoichiometries typically observed for the selected dietary phenols (especially the flavonoids, see Table 1) show that repeated $\mathrm{H}$-atom transfers take place not only from the starting phenols but also from some of their primary oxidation products. Indeed, several reaction pathways are possible depending on the fate of the transient aryloxyl radicals (Dangles, 2012): dimerization, disproportionation, scavenging of a second DPPH radical or possible reduction by a second antioxidant (with regeneration of the phenol).

When the data in the present study are compared to previous data recorded in $\mathrm{MeOH}$ (Goupy et al., 2003; Roche et al., 2005), the following remarks can be made:

- The rate constant for the first $\mathrm{H}$-atom abstraction $k_{1}$ is higher (by a factor of 1-5 depending on phenols) in the mildly acidic micelle environment. This acceleration may reflect not only favourable confinement and orientation of reagents in micelles (Chat, Najar, \& Dar, 2013; Noipa et al., 2011) but also a shift of the mechanism from $\mathrm{H}$-transfer to electron-transfer because of the increased polarity (Di Meo et al., 2013).

- The partial stoichiometry is lower in the mildly acidic micellar solution ( $n=1-2$ vs. $2-3$ in $\mathrm{MeOH}$ ), a result suggesting that disproportionation of the aryloxyl radicals may be impeded in micelles by interactions with the surfactant. However, the overall antioxidant stoichiometry remains high (even higher than in $\mathrm{MeOH}$ ), thus showing that globally phenol oxidation is exhaustive and results in the scavenging of several DPPH equivalents.

In food and in the GI tract, dietary phenols can come into contact with macromolecules such as polysaccharides (starch, fibres) and proteins. In this work, $\beta$-cyclodextrin $(\beta-C D)$, a natural macrocycle and a pertinent starch model, and bovine serum albumin (BSA), a common food protein, were studied for their possible impact on the phenols' H-donating capacity.

This impact can be anticipated in two ways:

- The macromolecules could substantially bind the dietary phenols, therefore increasing the phenol fraction in the aqueous phase (at the expense of the micelle-bound fraction) and lowering the overall activity.

- The macromolecules, especially BSA, could interfere with the fate of the aryloxyl and $o$-quinone intermediates.

Overall, the kinetic data (Table 1 ) revealed that the impact of $\beta-C D$ and BSA was actually weak. Regarding the rate constant of the first $\mathrm{H}$-atom transfer, this weak influence could simply reflect the relatively low affinity of the phenols for $\beta-C D$ and BSA (Table 1 supplementary) and consequently the small fraction of complexes in the aqueous phase. Under the conditions of $k_{1}$ estimation ( $75 \mu \mathrm{M}$ phenol $+125 \mu \mathrm{M} \beta-\mathrm{CD}$ or BSA), the percentage values of bound phenol for $K_{b}$ values of $10^{2}, 10^{3}, 10^{4}$ and $10^{5} \mathrm{M}^{-1}$ are respectively $1,10,47$ and $86 \%$. Thus, only flavonol-BSA binding (to a lesser degree, catechin- $\beta$-CD binding) seems strong enough (Table 1 supplementary) to retain the ligands in the aqueous phase. Although BSA indeed slows down the reaction between the flavonols and DPPH (Table 1), its influence is no stronger than that of $\beta$-CD despite the weaker affinity of the macrocycle for the flavonols. In fact, the most significant decrease in $k_{1}$ value (a factor ca. 4 ) is observed for the quercetin- $\beta$-CD couple. In that case, it can be hypothesized that the Brij35 micelles stabilize the inclusion complex for a more efficient sequestration of quercetin at the interface. Finally, olive phenols are largely insensitive to the presence of $\beta-C D$ and BSA. Although their binding to BSA has not been investigated, it is probably quite weak. Overall, both 
hydroxytyrosol and oleuropein must be largely available for an antioxidant action within the dietary bolus.

Regarding the total stoichiometry, it must be noted that BSA itself (unlike $\beta-C D$ ) expresses a weak DPPH-scavenging activity. Its $n_{\text {tot }}$ value of 1.66 (Table 1 ) is probably mainly due to the reactivity of its single free cysteine residue (Cys-34). If quercetin (Q) and BSA independently scavenged the DPPH radical (additive behaviour), an overall stoichiometry $n_{\text {tot }}^{\text {add }}=n_{\text {tot }}(\mathrm{Q})+5 n_{\text {tot }}(\mathrm{BSA}) \approx 13$ would be expected (initial BSA/phenol molar ratio $=5$ ). This value is much higher than the experimental value, which is actually even lower than the stoichiometry of quercetin alone (ca. 5). It can thus be concluded that, if BSA has only a moderate impact on the rate of DPPH scavenging by quercetin, it drastically lowers the total number of DPPH radicals that can be reduced per quercetin molecule. Similar considerations can be applied to the other selected phenols. Indeed, even if olive phenols give slightly higher $n_{\text {tot }}$ values in the presence of BSA, the increase remains much lower than expected from an additive behaviour. This interesting result suggests that during radical scavenging the $o$-quinone intermediates are at least partially trapped by BSA, possibly by nucleophilic addition of Cys-34, so that the DPPH-scavenging capacity of BSA is lost and the overall stoichiometry remains close to the value estimated in the absence of BSA. In oxidative conditions, serum albuminpolyphenol covalent coupling has already been evidenced (Kaldas, Walle, van der Woude, McMillan, \& Walle, 2005). In particular, autoxidation of chlorogenic acid $(\mathrm{pH} 9)$ in the presence of BSA and subsequent coupling of the $o$-quinone thus formed to BSA was shown to occur mainly at Cys and Lys residues (Rawel, Rohn, Kruse, \& Kroll, 2002). BSA was also found to lower the capacity of quercetin to scavenge the bulky $\mathrm{ABTS}^{+}{ }^{+}$radical cation (Arts, Haenen, Voss, \& Bast, 2001). Consistently, quercetin-BSA covalent adducts were found less efficient than quercetin at reducing ABTS ${ }^{+}$ (Rohn, Rawel, \& Kroll, 2004).

\subsection{Reduction of activated haem iron}

Oxidative stress in the stomach can arise from the combination of metmyoglobin ( $\left.\mathrm{MbFe}^{\mathrm{III}}-\mathrm{OH}\right)$, the pigment of red meat and main dietary iron form, with $\mathrm{H}_{2} \mathrm{O}_{2}$ and/or lipid hydroperoxides inevitably contaminating PUFA-containing food (e.g., plant oils and sauces, fish, dairy products, meat). Indeed, MbFe ${ }^{\text {IIII-OH }}$ can bind hydroperoxides and promote homolytic cleavage of the peroxide bond to generate hypervalent haem species $\left(\mathrm{Fe}^{\mathrm{IV}}\right)$ that are especially reactive in mildly acidic conditions and thus can initiate lipid peroxidation in the gastric compartment (Dangles, 2012; Kanner \& Lapidot, 2001). As lipid peroxyl radicals thus produced can oxidize proteins and (pro)vitamins such as vitamin $\mathrm{E}$ and $\beta$-carotene, haem-induced lipid peroxidation in the stomach may be regarded as highly deleterious to the nutritional value of the dietary bolus. The concomitant formation of electrophilic lipid oxidation products, such as aldehydes, possibly involved in postprandial modifications of plasma low-density lipoproteins, is also considered a risk factor in the initiation of cardiovascular disease (Kanner et al., 2012). Hence, the ability of the most abundant dietary antioxidants, i.e. plant phenols, to reduce hypervalent haem species, thereby inhibiting the initiation of lipid peroxidation, is potentially a relevant antioxidant mechanism in humans.

In this work, hypervalent haem was simply produced by mixing MbFe ${ }^{\mathrm{III}}-\mathrm{OH}$ and $\mathrm{H}_{2} \mathrm{O}_{2}$ (1 equiv.). In the reaction, perferrylmyoglobin $\mathrm{Mb} \cdot \mathrm{Fe}^{\mathrm{IV}}=\mathrm{O}$ is formed, which displays a Trp and/or Tyr radical that is quickly dissipated through the protein (Carlsen, Moller, \& Skibsted, 2005). Ferrylmyoglobin $\mathrm{Mb}^{\mathrm{ox}} \mathrm{Fe}^{\mathrm{IV}}=\mathrm{O}$ thus produced is relatively stable over a few minutes (slow first-order decay by auto-reduction). Its reduction to $\mathrm{Mb}^{\mathrm{ox}} \mathrm{Fe}^{\mathrm{III}}-\mathrm{OH}$ by phenolic antioxidants can be readily monitored by conventional UV-visible spectroscopy (Lorrain, Dufour, et al., 2010) (Fig 1). The reaction

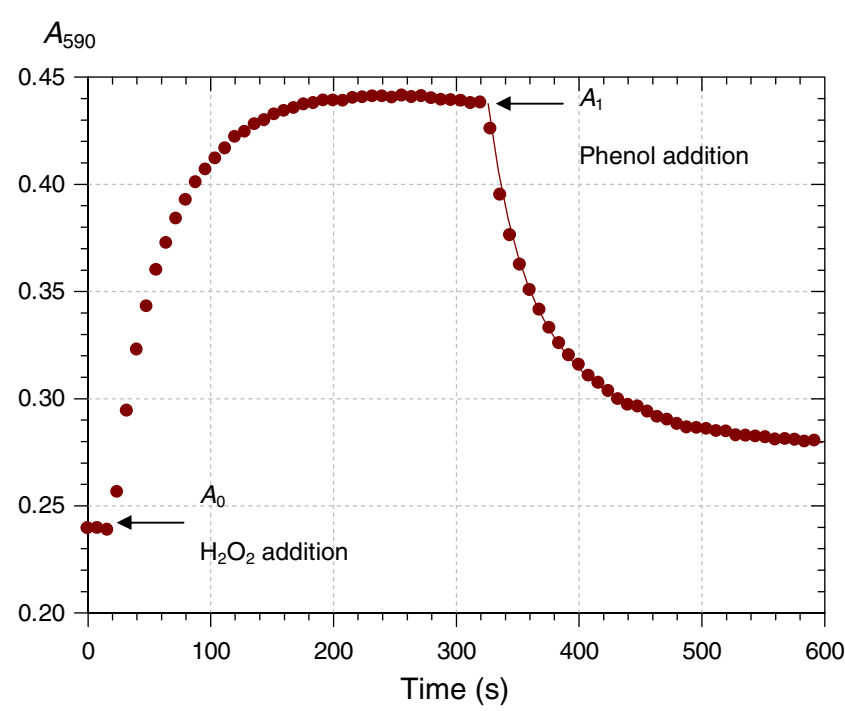

Fig. 1. Activation of metmyoglobin $(60 \mu \mathrm{M})$ by $\mathrm{H}_{2} \mathrm{O}_{2}$ (1 equiv.) and subsequent reduction of ferrylmyoglobin by hydroxytyrosol ( 1 equiv.), $\mathrm{pH} 5.8$ phosphate buffer containing BSA ( 3 equiv.), $25^{\circ} \mathrm{C}$. The solid line is the result of the curve-fitting.

is carried out in the presence of BSA ( 3 equiv.), which was shown to bind $\mathrm{MbFe}{ }^{\mathrm{III}}-\mathrm{OH}$ and stabilize $\mathrm{Mb}^{\mathrm{ox}} \mathrm{Fe}^{\mathrm{IV}}=\mathrm{O}$ in mildly acidic conditions by minimizing the competing formation of a redox-inert green pigment (covalent coupling between haem and the globin protein).

The decay of the visible absorbance at $590 \mathrm{~nm}\left(\lambda_{\max }\right.$ of $\mathrm{Mb}^{\mathrm{ox}} \mathrm{Fe}^{\mathrm{IV}}=0$ ) was quantitatively analyzed using Eqs. (1) and (2):

$A_{590}=\varepsilon_{0}\left(M b F e^{I I I}-O H\right)+\varepsilon_{1}\left(M b^{o x} F e^{I V}=O\right)+\varepsilon_{2}\left(M b^{o x} F e^{I I I}-O H\right)$

$$
\begin{aligned}
-\frac{d}{d t}\left(M b^{o x} F e^{I V}=O\right) & =-\frac{d}{d t}(A r O H)=\frac{d}{d t}\left(M b^{o x} F e^{I I I}-O H\right) \\
& =k_{r}\left(M b^{o x} F e^{I V}=O\right)(A r O H)
\end{aligned}
$$

Regarding the molar absorption coefficients of the different haem species, one has: $\varepsilon_{0}=A_{0} / C_{0}, A_{0}$ being the initial absorbance before $\mathrm{H}_{2} \mathrm{O}_{2}$ addition and $\mathrm{C}_{0}$ the total haem concentration, $\varepsilon_{1}=9450 \mathrm{M}^{-1} \mathrm{~cm}^{-1}$ (estimated from the kinetics of $\mathrm{Mb}^{\mathrm{OX}} \mathrm{Fe}^{\mathrm{IV}}=\mathrm{O}$ formation in the same conditions, see Lorrain, Dufour, et al., 2010), $\varepsilon_{2}$ being an adjustable parameter that is deduced from the curve-fitting as well as the second-order rate constant of $\mathrm{Mb}^{\mathrm{ox}} \mathrm{Fe}^{\mathrm{IV}}=\mathrm{O}$ reduction $k_{\mathrm{r}}$. The concentrations of $\mathrm{MbFe}{ }^{\mathrm{III}}-\mathrm{OH}$ and $\mathrm{Mb}^{\mathrm{ox}} \mathrm{Fe}^{\mathrm{IV}}=\mathrm{O}$ at the time of antioxidant addition (time zero of the kinetic analysis) are $C_{0}-\frac{A_{1}-A_{0}}{\varepsilon_{1}-\varepsilon_{0}}$ and $\frac{A_{1}-A_{0}}{\varepsilon_{1}-\varepsilon_{0}}$, respectively, $A_{1}$ being the absorbance at the time of antioxidant addition.

The curve-fittings of the decay of $A_{590}$ featuring the reduction of $\mathrm{Mb}^{\mathrm{ox}} \mathrm{Fe}^{\mathrm{IV}}=\mathrm{O}$ by the selected phenols were all quite satisfactory and yielded consistent values of $\varepsilon_{2}$ (Table 2 supplementary). The corresponding rate constants are of the same order of magnitude (300-800 $\mathrm{M}^{-1} \mathrm{~s}^{-1}$ ). In particular, the $k_{\mathrm{r}}$ values for hydroxytyrosol and oleuropein are $474( \pm 4)$ and $348( \pm 6) \mathrm{M}^{-1} \mathrm{~s}^{-1}$, respectively. Thus, olive phenols can reach the haem crevice of BSA-bound ferrylmyoglobin and reduce $\mathrm{Fe}^{\mathrm{IV}}$, which points to their potential ability to inhibit haem-induced PUFA peroxidation at the initiation stage. By contrast, $\boldsymbol{\alpha}$-tocopherol does not reduce hypervalent haem, nor interfere in its reduction by the dietary phenols (data not shown).

\subsection{Inhibition of the metmyoglobin-induced peroxidation of linoleic acid}

Our previous studies on sunflower oil emulsions have shown that dietary phenols can inhibit the metmyoglobin-induced lipid 
peroxidation in the early phase of gastric digestion when the $\mathrm{pH}$ is still relatively high (pH 5-6) (Lorrain, Dangles, Genot, \& Dufour, 2010; Lorrain, Dangles, Loonis, Armand, \& Dufour, 2012). When the $\mathrm{pH}$ decreases alongside the gastric emptying, the haematin cofactor becomes dissociated from the globin protein and probably more embedded into the lipid phase and thus less accessible to phenols. Although oil-in-water emulsions are more relevant models of the gastric content than simple PUFA micelles, the latter provide adequate systems for investigating mechanisms (Goupy, Vulcain, Caris-Veyrat, \& Dangles, 2007; Sy et al., 2013). Moreover, substantial concentrations of free fatty acids (5-30\%) are released in the stomach due to the action of gastric lipase (Golding \& Wooster, 2010). In this work, the ability of olive phenols to inhibit the metmyoglobin-induced peroxidation of linoleic acid in Brij35 micelles was investigated at pH 5.8 in the presence or absence of $\alpha$-tocopherol, the typical endogenous antioxidant protecting PUFA chains in oils, emulsions and membranes. It is believed that the combination of metmyoglobin (the main form of dietary iron), linoleic acid (possibly released from dietary triglycerides by the gastric lipase) and a mildly acidic medium corresponding to the first hour of gastric digestion (Gobert et al., 2014; Tyssandier et al., 2003) provides a simple but relevant model of lipid oxidation in the stomach.

Olive phenols were shown to be potent inhibitors of PUFA peroxidation in SDS micelles ( $\mathrm{pH} 7.4$ ) where the reaction is initiated by the hydrophilic peroxyl radicals generated by thermal decomposition of diazo compound AAPH (Roche et al., 2005). A detailed kinetic analysis suggested that the inhibition proceeds by direct reduction of the initiating peroxyl radicals, rather than by breaking of the propagation chain, i.e. by reduction of the lipid peroxyl radicals.

By contrast, in this work, both hydroxytyrosol and oleuropein came up as weak inhibitors of the metmyoglobin-induced peroxidation of linoleic acid ( $\mathrm{LH}, \mathrm{H}$ representing one of the labile bisallylic $\mathrm{H}$-atoms) in $\mathrm{pH} 5.8$ Brij35 micellar solution. Indeed, the kinetic profiles for the accumulation of conjugated dienes (CDs, mostly hydroperoxide regio- and stereoisomers LOOH, Vulcain, Goupy, Caris-Veyrat, \& Dangles, 2005) and the consumption of dioxygen display short ill-defined induction periods (time periods of totally inhibited peroxidation) (Fig. 2). However, after the induction period, the peroxidation rate ( $C D$ accumulation) remains lower than in the control. Given the independently demonstrated ability of olive phenols to reduce ferrylmyoglobin, the olive phenols are proposed to inhibit the initiation step by reducing the hypervalent haem species responsible for the formation of the propagating lipid peroxyl radicals LOO.$^{1}$ By contrast, $\alpha$-tocopherol (Toc) strongly inhibits $\mathrm{CD}$ accumulation and $\mathrm{O}_{2}$ consumption with well-defined concentration-dependent induction periods (Fig. 2). As $\alpha$-tocopherol does not reduce hypervalent haem, this observation reflects its typical behaviour as a chain-breaking antioxidant by $\mathrm{H}$-atom transfer to LOO: Moreover, after the end of the induction phase (complete consumption of Toc), CD accumulation resumes to become as fast as in the control.

It is noteworthy that $\mathrm{CD}$ accumulation remains lower than $\mathrm{O}_{2}$ consumption in the course of haem-induced linoleic acid peroxidation (Fig. 2). Remarkably, $\mathrm{O}_{2}$ consumption is already significant during the induction period of Toc-inhibited peroxidation while CDs have not started to accumulate yet. These observations are consistent with the mechanism of haem-Fe ${ }^{\mathrm{IV}}$ formation (Fig. 3). Indeed, during the initiation step, the homolytic cleavage of LOOH triggers $\mathrm{O}_{2}$ consumption and the subsequent formation of ketodienes

\footnotetext{
${ }^{1}$ In the absence of added $\mathrm{H}_{2} \mathrm{O}_{2}$, the hypervalent haem species involved in the initiation of lipid peroxidation is elusive and probably distinct from ferrylmyoglobin (Lorrain, Dufour, et al., 2010). Its precise structure being unknown, it is simply
} denoted $\mathrm{MbFe}^{\mathrm{IV}}$.

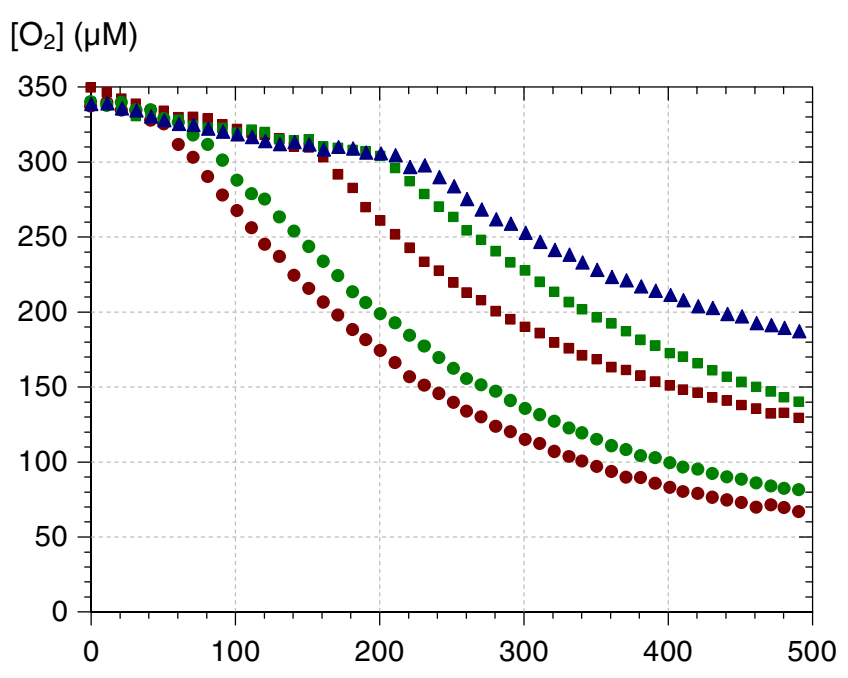

[CD] $(\mu \mathrm{M})$

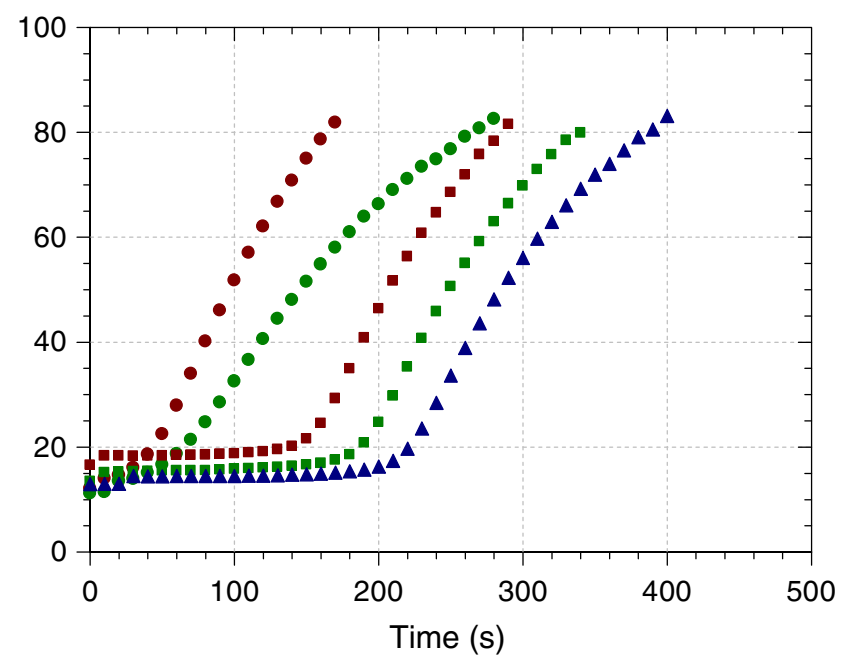

Fig. 2. Inhibition of the metmyoglobin-induced peroxidation of linoleic acid by hydroxytyrosol (HT), $\alpha$-tocopherol (Toc) and a combination of both. CD concentration calculated from $A(234 \mathrm{~nm})$ assuming $\varepsilon=24 \times 10^{3} \mathrm{M}^{-1} \mathrm{~cm}^{-1}$. : $0.2 \mu \mathrm{M} \mathrm{HT}$, : $1 \mu \mathrm{M}$ HT, $\square: 0.8 \mu \mathrm{M}$ Toc, $\square: 1 \mu \mathrm{M}$ Toc, $\mathbf{\Delta}: 0.8 \mu \mathrm{M}$ Toc $+0.2 \mu \mathrm{M}$ HT.

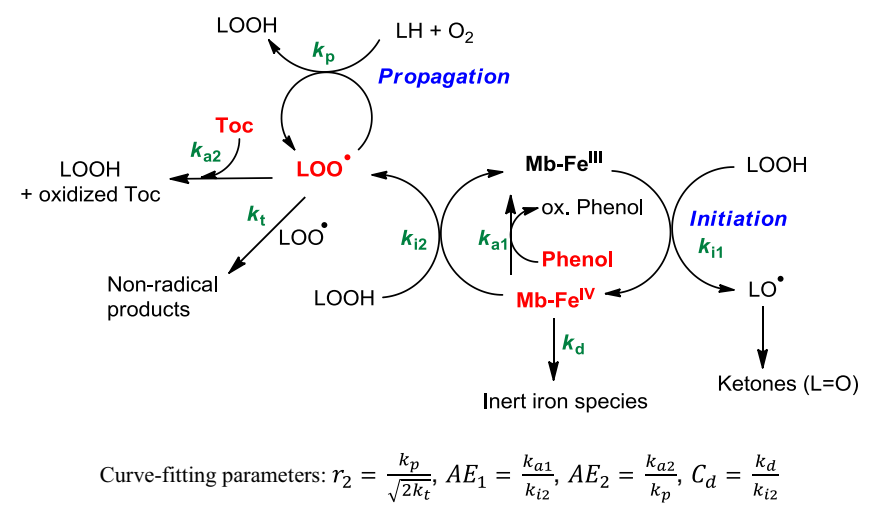

Fig. 3. The mechanism of metmyoglobin-induced lipid peroxidation and its inhibition by phenolic compounds and $\alpha$-tocopherol (Toc).

(Lorrain, Dufour, et al., 2010). It also compensates for the moderate accumulation of CDs that would otherwise be observed.

The kinetic profile of $\mathrm{CD}$ accumulation can be quantitatively accounted for using a kinetic model (Fig. 3) developed by Sy 
Version définitive du manuscrit publiée dans / Final version of the manuscript published in :

Food Chemistry (2016), Vol. 213, p. 135-142, DOI: 10.1016/j.foodchem.2016.06.076

Journal homepage : www.elsevier.com/locate/foodchem

Table 2

Kinetic parameters for the inhibition of the metmyoglobin-induced peroxidation of linoleic acid by phenols in micelles (pH 5.8). ${ }^{a}$

\begin{tabular}{|c|c|c|c|c|c|}
\hline Phenol/ $\mu \mathrm{M}$ & $r_{2} / \mathrm{M}^{-1 / 2} \mathrm{~s}^{-1 / 2}$ & $k_{\mathrm{i} 1} / \mathrm{M}^{-1} \mathrm{~s}^{-1}$ & $A E_{1}$ or $A E_{2}$ & $n$ & $C_{\mathrm{d}} / \mu \mathrm{M}$ \\
\hline Control & $4.4( \pm 0.9)$ & $870( \pm 450)$ & - & - & - \\
\hline \multicolumn{6}{|c|}{ Hydroxytyrosol (HT) } \\
\hline 0.2 & 4.4 & 870 & 1070 & $0.5( \pm 0.1)$ & $2.7( \pm 0.1)$ \\
\hline 0.8 & 4.4 & 870 & $700( \pm 270)$ & $0.20( \pm 0.02)$ & $5.0( \pm 0.1)$ \\
\hline 1.0 & 4.4 & 870 & 880 & $0.11( \pm 0.02)$ & $4.8( \pm 0.1)$ \\
\hline \multicolumn{6}{|c|}{ Oleuropein (OL) } \\
\hline 0.2 & 4.4 & 870 & 1400 & $0.5( \pm 0.2)$ & $2.3( \pm 0.2)$ \\
\hline \multirow[t]{2}{*}{0.8} & 4.4 & 870 & 1230 & $0.18( \pm 0.03)$ & $2.2( \pm 0.1)$ \\
\hline & & & 1080 & $0.15( \pm 0.03)$ & $2.6( \pm 0.1)$ \\
\hline 1.0 & 4.4 & 870 & $410( \pm 40)$ & $0.25( \pm 0.01)$ & $4.1( \pm 0.1)$ \\
\hline \multicolumn{6}{|c|}{$\alpha$-Tocopherol (Toc) } \\
\hline 0.2 & 4.4 & 870 & $670( \pm 120)$ & $1.1( \pm 0.2)$ & $0.5( \pm 0.2)$ \\
\hline 0.8 & 4.4 & 870 & $470( \pm 150)$ & $1.2( \pm 0.1)$ & 0 \\
\hline \multirow[t]{2}{*}{1.0} & 4.4 & 870 & $430( \pm 70)$ & $0.93( \pm 0.03)$ & 0 \\
\hline & & & $530( \pm 160)$ & $1.1( \pm 0.1)$ & \\
\hline \multicolumn{6}{|l|}{$T o c+H T$} \\
\hline \multirow[t]{2}{*}{$0.2+0.8$} & 4.4 & 870 & $10^{3}$ & $0.49( \pm 0.06)$ & $4.0( \pm 0.2)$ \\
\hline & & & $5 \times 10^{2}$ & $<0.1$ & \\
\hline \multirow[t]{2}{*}{$0.8+0.2$} & 4.4 & 870 & $10^{3}$ & $<0.1$ & $1.3( \pm 0.1)$ \\
\hline & & & $5 \times 10^{2}$ & $1.5( \pm 0.1)$ & \\
\hline \multicolumn{6}{|l|}{$\mathrm{Toc}+\mathrm{OL}$} \\
\hline \multirow[t]{2}{*}{$0.2+0.8$} & 4.4 & 870 & $10^{3}$ & $0.54( \pm 0.01)$ & $3.5( \pm 0.2)$ \\
\hline & & & $5 \times 10^{2}$ & $<0.1$ & \\
\hline \multirow[t]{2}{*}{$0.8+0.2$} & 4.4 & 870 & $10^{3}$ & $<0.1$ & $0.5( \pm 0.1)$ \\
\hline & & & $5 \times 10^{2}$ & $1.1( \pm 0.1)$ & \\
\hline
\end{tabular}

a From the mathematical analysis of the $\mathrm{A}(234 \mathrm{~nm}) v s$. time curves according to the model developed in Sy et al. (2013) $(r>0.995)$. Values between brackets are the

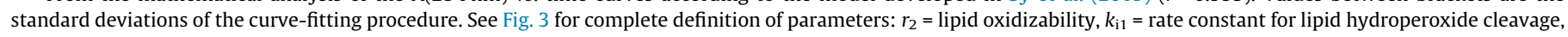

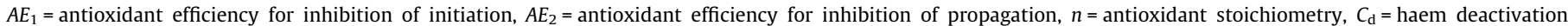
parameter.

et al. (2013) with the following adjustable parameters: the oxidizability of linoleic acid $r_{2}$, the rate constant $k_{\mathrm{i} 1}$ of LOOH cleavage by $\mathrm{MbFe}^{\text {III }}$ (both being estimated by curve-fitting of the control curve), the antioxidant efficiency for inhibiting initiation $A E_{1}$ (a measure of the antioxidant's ability to reduce hypervalent haem $\left.\mathrm{MbFe}^{\mathrm{IV}}\right)$, the antioxidant efficiency for inhibiting propagation $A E_{2}$ (a measure of the antioxidant's ability to reduce LOO-), the antioxidant stoichiometry $n$ (number of $\mathrm{MbFe}^{\mathrm{IV}}$ and/or LOO equivalents reduced per antioxidant molecule, antioxidant concentration used in the curve-fittings $=n \times$ experimental concentration) and parameter $C_{\mathrm{d}}$ (homologous to a concentration), a measure of $\mathrm{MbFe}^{\mathrm{IV}}$ deactivation (conversion into inert iron species).

With the olive phenols, pure inhibition of initiation is assumed $\left(A E_{2}=0\right)$. Although only the order of magnitude of $A E_{1}$ could be obtained (Table 2), all curve-fittings were satisfactory (Fig. 4). Surprisingly, the $n$ values are very low $(<0.5)$, an observation suggesting that, in the presence of PUFA micelles, only a fraction of the olive antioxidants has access to the haem crevice for the reduction of $\mathrm{MbFe}^{\mathrm{IV}}$. Under similar conditions, although chlorogenic acid was also weakly active, quercetin, rutin and catechin performed much better (Goupy, Bautista-Ortin, Fulcrand, \& Dangles, 2009; Goupy et al., 2007; Sy, Dangles, Borel, \& Caris-Veyrat, 2015). However, olive phenols or some of their oxidation products promote haem deactivation $\left(C_{\mathrm{d}}>0\right)$, possibly by direct iron binding.

For $\alpha$-tocopherol, pure inhibition of propagation is assumed $\left(A E_{1}=0\right)$. The results of the curve-fitting (Fig. 4, Table 2) suggest that Toc is able to reduce one peroxyl radical $(n \approx 1)$ but does not significantly promote haem deactivation $\left(C_{d}=0\right)$, in agreement with a propagation rate roughly equal to that of the control experiment.

Investigating combinations of antioxidants shows that a 1:4 mixture of hydroxytyrosol and $\alpha$-tocopherol provides an extended protection combining both advantages of a well-defined induction phase ( $\alpha$-tocopherol's role) and a subsequent moderate peroxidation rate (hydroxytyrosol's role) (Figs. 2 and 4A). This experimental peroxidation curve can be analyzed using the mean $A E_{1}$ and $A E_{2}$ values determined for the individual antioxidants (olive phenols: $A E_{1} \approx 10^{3}$, Toc: $A E_{2} \approx 5 \times 10^{2}$ ) with $C_{\mathrm{d}}$ and both $n$ values as adjustable parameters. Interestingly, the calculations suggest a pure $\alpha$-tocopherol behaviour ( $n$ for HT $\approx 0$ ) and a prolongation of the protection ( $n$ for Toc $\approx 1.5 v s .1 .1$ in the absence of HT) afforded by the chain-breaking antioxidant. Moreover, a theoretical peroxidation curve assuming additivity was generated from the $n$ values determined for the individual antioxidants (same $C_{\mathrm{d}}$ value as for the experimental curve). Comparing the experimental and theoretical curves confirms the moderate synergism between the two antioxidants under those conditions.

The same analysis was repeated with a 1:4 mixture of hydroxytyrosol and $\alpha$-tocopherol. In this case, a pure HT behaviour emerged ( $n$ for Toc $\approx 0$ ) and no synergism was observed. For a total antioxidant concentration of $1 \mu \mathrm{M}$, it is clear from both the curves of $\mathrm{CD}$ accumulation and $\mathrm{O}_{2}$ consumption that a 4:1 Toc + HT mixture is much more protective than the corresponding 1:4 Toc + HT mixture (Fig. 3 supplementary).

Finally, combinations of oleuropein and $\alpha$-tocopherol failed to deliver synergism even when Toc was in excess (Fig. 4B).

\section{Conclusion}

In this work, the popular DPPH test (typically carried out in $\mathrm{MeOH}$ ) has been extended to a system (mildly acidic aqueous micellar solution) that is more relevant to food and the gastric conditions, while keeping the high level of rationalization (estimation of rate constants and stoichiometries) already achieved in our previous work (Goupy et al., 2003). This extension also allows the possible impact of food macromolecules (proteins, polysaccharides) on the radical-scavenging activity to be assessed, as exemplified here with $\beta$-cyclodextrin and bovine serum albumin. 
Version définitive du manuscrit publiée dans / Final version of the manuscript published in :

Food Chemistry (2016), Vol. 213, p. 135-142, DOI: 10.1016/j.foodchem.2016.06.076

Journal homepage : www.elsevier.com/locate/foodchem
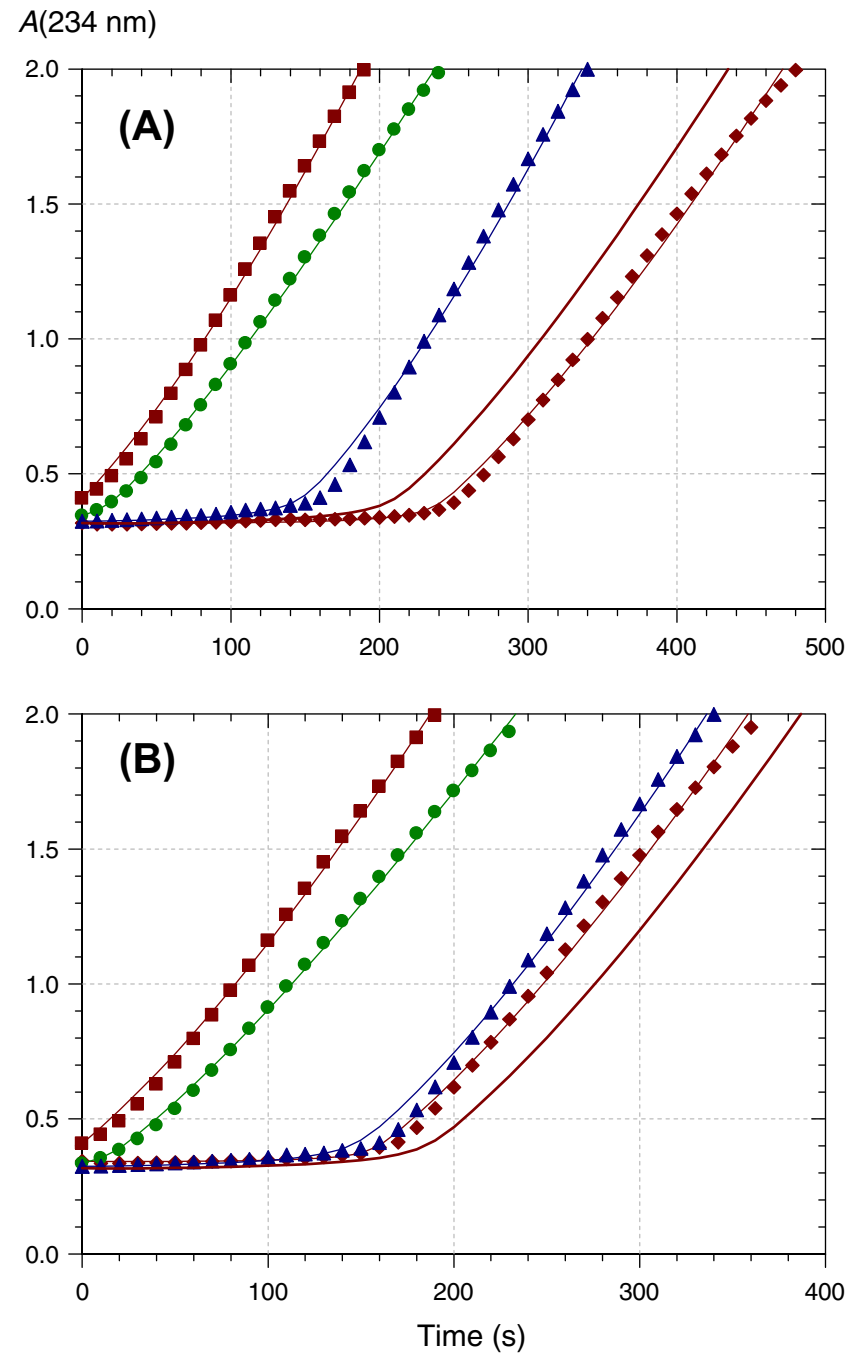

Fig. 4. Inhibition of the metmyoglobin-induced peroxidation of linoleic acid by olive phenols, $\alpha$-tocopherol (Toc) and a combination of both. $\square$ : control, $0: 0.2 \mu \mathrm{M}$ olive phenol, $\mathbf{\Delta}: 0.8 \mu \mathrm{M}$ Toc, $\diamond: 0.8 \mu \mathrm{M}$ Toc $+0.2 \mu \mathrm{M}$ HT, - : simulation of mixture assuming additivity $\left(A E_{1}, A E_{2}\right.$ and $n$ from experimental curves of individual antioxidants, $C_{d}$ from experimental curve of mixture). A) Hydroxytyrosol. B) Oleuropein.

Despite major interest in their application as bioactive food phenols, olive phenols have rarely been investigated for their ability to inhibit lipid peroxidation under conditions that are relevant to food or the GI tract (oxidation initiated by dietary iron). Surprisingly, hydroxytyrosol and oleuropein, although intrinsically potent antioxidants, are modest inhibitors of haem-induced lipid peroxidation. Indeed, the efficiency of the olive phenols in transferring electrons or $\mathrm{H}$-atoms to radicals and hypervalent haem species is comparable to that of potent flavonoids. Thus, their poorer performance in inhibiting the haem-induced peroxidation of linoleic acid may be ascribed to interactions with micelles (already suggested by the DPPH test) that oppose their access to the haem without conferring on them a favourable access to the chain-propagating lipid peroxyl radicals (the $\alpha$-tocopherol's asset). However, hydroxytyrosol-micelle interactions could well induce a favourable interplay with $\alpha$-tocopherol. Indeed, low concentrations of hydroxytyrosol, the main olive oil antioxidant, substantially potentiate the chain-breaking antioxidant $\alpha$-tocopherol in its inhibition of haem-induced lipid peroxidation. In other words, synergism with $\alpha$-tocopherol is required for hydroxytyrosol to express its full capacity to protect polyunsaturated fatty acids against oxidation initiated by dietary iron.
Overall, these antioxidant tests combine the advantages of a certain nutritional significance and of a simplicity compatible with a large screening of samples. We consider they could be preferred to more routine tests in the evaluation of natural antioxidants.

\section{Conflict of interest}

The authors declare no conflict of interest.

\section{Acknowledgments}

We thank Michèle Loonis (UMR408) for her help in the lipid peroxidation experiments.

\section{Appendix A. Supplementary data}

Supplementary data associated with this article can be found, in the online version, at http://dx.doi.org/10.1016/j.foodchem.2016. 06.076.

\section{References}

Arts, M. J. T. J., Haenen, G. R. M. M., Voss, H. P., \& Bast, A. (2001). Masking of antioxidant capacity by the interaction of flavonoids with protein. Food $\mathcal{E}$ Chemical Toxicology, 39, 787-791.

Bulotta, S., Celano, M., Massimo Lepore, S., Montalcini, T., Pujia, A., \& Russo, D. (2014). Beneficial effects of the olive oil phenolic components oleuropein and hydroxytyrosol: Focus on protection against cardiovascular and metabolic diseases. Journal of Translational Medicine, 12, 219-227.

Carlsen, C., Moller, J., \& Skibsted, L. (2005). Heme-iron in lipid oxidation. Coordination Chemistry Reviews, 249, 485-498.

Chat, O. A., Najar, M. H., \& Dar, A. A. (2013). Evaluation of reduction kinetics of 2,2diphenyl-1-picrylhydrazylradical by flavonoid glycoside rutin in mixed solventbased micellar media. Colloids \& Surfaces A: Physicochemical E Engineering Aspects, 436, 343-353.

Dangles, O. (2012). Antioxidant activity of plant phenols: Chemical mechanisms and biological significance. Current Organic Chemistry, 16, 692-714.

Del Rio, D., Rodriguez-Mateos, A., Spencer, J. P. E., Tognolini, M., Borges, G., \& Crozier, A. (2013). Dietary (poly)phenolics in human health: Structures, bioavailability, and evidence of protective effects against chronic diseases. Antioxidants $\mathcal{E}$ Redox Signaling, 18, 1818-1892.

Di Meo, F., Lemaur, V., Cornil, J., Lazzaroni, R., Duroux, J.-L., Olivier, Y., et al. (2013). Free radical scavenging by natural polyphenols: Atom versus electron transfer. Journal of Physical Chemistry A, 117, 2082-2092.

EFSA Panel on Dietetic Products, Nutrition and Allergies (2011). Scientific opinion on the substantiation of health claims related to polyphenols in olive. EFSA Journal, 9, 2033-2058.

Giordano, E., Dangles, O., Rakotomanomana, N., Baracchini, S., \& Visioli, F. (2015). 3$O$-Hydroxytyrosol glucuronide and 4-O-hydroxytyrosol glucuronide reduce endoplasmic reticulum stress in vitro. Food \& Function, 6, 3275-3281.

Gobert, M., Remond, D., Loonis, M., Buffiere, C., Sante-Lhoutellier, V., \& Dufour, C. (2014). Fruits, vegetables and their polyphenols protect dietary lipids from oxidation during gastric digestion. Food E Function, 5, 2166-2174.

Golding, M., \& Wooster, T. J. (2010). The influence of emulsion structure and stability on lipid digestion. Current Opinion in Colloid Interface Science, 15, 90-101.

Goupy, P., Bautista-Ortin, A. B., Fulcrand, H., \& Dangles, O. (2009). Antioxidant activity of wine pigments derived from anthocyanins: Hydrogen transfer reactions to the DPPH radical and inhibition of the heme-induced peroxidation of linoleic acid. Journal of Agricultural \& Food Chemistry, 57, 5762-5770.

Goupy, P., Dufour, C., Loonis, M., \& Dangles, O. (2003). Quantitative kinetic analysis of hydrogen transfer reactions from dietary polyphenols to the DPPH radical. Journal of Agricultural \& Food Chemistry, 51, 615-622.

Goupy, P., Vulcain, E., Caris-Veyrat, C., \& Dangles, O. (2007). Dietary antioxidants as inhibitors of the heme-induced peroxidation of linoleic acid: Mechanism of action and synergism. Free Radical Biology \& Medicine, 43, 933-946.

Jerman Klen, T., Golc Wondra, A., Vrhovsek, U., Sivilotti, P., \& Mozetic Vodopivec, B. (2015). Olive fruit phenols transfer, transformation, and partition trail during laboratory-scale olive oil processing. Journal of Agricultural E' Food Chemistry, 63, 4570-4579.

Kaldas, M. I., Walle, U. K., van der Woude, H., McMillan, J. M., \& Walle, T. (2005). Covalent binding of the flavonoid quercetin to human serum albumin. Journal of Agricultural \& Food Chemistry, 53, 4194-4197.

Kanner, J., Gorelik, S., Roman, S., \& Kohen, R. (2012). Protection by polyphenols of postprandial human plasma and low-density lipoprotein modification: The stomach as a bioreactor. Journal of Agricultural \& Food Chemistry, 60, 8790-8796. 
Version définitive du manuscrit publiée dans / Final version of the manuscript published in :

Food Chemistry (2016), Vol. 213, p. 135-142, DOI: 10.1016/j.foodchem.2016.06.076

Journal homepage : www.elsevier.com/locate/foodchem

Kanner, J., \& Lapidot, T. (2001). The stomach as a bioreactor: Dietary lipid peroxidation in the gastric fluid and the effects of plant-derived antioxidants. Free Radical Biology \&' Medicine, 31, 1388-1395.

Lorrain, B., Dangles, O., Genot, C., \& Dufour, C. (2010). Chemical modeling of hemeinduced lipid oxidation in gastric conditions and inhibition by dietary polyphenols. Journal of Agricultural \& Food Chemistry, 58, 676-683.

Lorrain, B., Dangles, O., Loonis, M., Armand, M., \& Dufour, C. (2012). Dietary ironinitiated lipid oxidation and its inhibition by polyphenols in gastric conditions. Journal of Agricultural \&' Food Chemistry, 60, 9074-9081.

Lorrain, B., Dufour, C., \& Dangles, O. (2010). Influence of serum albumin and the flavonol quercetin on the peroxidase activity of metmyoglobin. Free Radical Biology \&' Medicine, 48, 1162-1172.

Mikkelsen, A., \& Skibsted, L. H. (1995). Acid-catalysed reduction of ferrylmyoglobin: Product distribution and kinetics of autoreduction and reduction by NADH. Zeitschrift für Lebensmittel-Untersuchung und-Forschung, 200, 171-177.

Noipa, T., Srijaranai, S., Tuntulani, T., \& Ngeontae, W. (2011). New approach for evaluation of the antioxidant capacity based on scavenging DPPH free radical in micelle systems. Food Research International, 44, 798-806.

Orozco-Solano, M. I., Ferreiro-Vera, C., Priego-Capote, F., \& Luque de Castro, M. D. (2012). Automated method for determination of olive oil phenols and metabolites in human plasma and application in intervention studies. Journal of Chromatography A, 1258, 108-116.

Rawel, H. M., Rohn, S., Kruse, H. P., \& Kroll, J. (2002). Structural changes induced in bovine serum albumin by covalent attachment of chlorogenic acid. Food Chemistry, 78, 443-455.
Roche, M., Dufour, C., Mora, N., \& Dangles, O. (2005). Antioxidant activity of olive phenols: Mechanistic investigation and characterization of oxidation products by mass spectrometry. Organic \& Biomolecular Chemistry, 3, 423-430.

Rohn, S., Rawel, H. M., \& Kroll, J. (2004). Antioxidant activity of protein-bound quercetin. Journal of Agricultural \& Food Chemistry, 52, 4725-4729.

Sanchez de Medina, V., Priego-Capote, F., \& Luque de Castro, M. D. (2015) Characterization of monovarietal virgin olive oils by phenols profiling. Talanta $132,424-432$.

Sy, C., Caris-Veyrat, C., Dufour, C., Boutaleb, M., Borel, P., \& Dangles, O. (2013). Inhibition of iron-induced lipid peroxidation by newly identified bacterial carotenoids in model gastric conditions. Comparison with common carotenoids. Food E' Function, 4, 698-712.

Sy, C., Dangles, O., Borel, P., \& Caris-Veyrat, C. (2015). Interactions between carotenoids from marine bacteria and other micronutrients: Impact on stability and antioxidant activity. Marine Drugs, 13, 7020-7039.

Tyssandier, V., Reboul, E., Dumas, J. F., Bouteloup-Demange, C., Armand, M. Marcand, J., et al. (2003). Processing of vegetable-borne carotenoids in the human stomach and duodenum. American Journal of Physiology, 284 G913-G923.

Visioli, F., \& Bernardini, E. (2011). Extra virgin olive oil's polyphenols, biological activities. Current Pharmaceutical Design, 17, 786-804.

Vulcain, E., Goupy, P., Caris-Veyrat, C., \& Dangles, O. (2005). Inhibition of the metmyoglobin-induced peroxidation of linoleic acid by dietary antioxidants: Action in the aqueous vs. lipid phase. Free Radical Research, 39, 547-563. 